\section{Campo profissional e arquitetura nos anos 1980. Um olhar através da revista "Casa e Jardim".}

Professional field and architecture in the 1980s. A view through "Casa e Jardim" magazine.

Dely Bentes*

*Mestre (2006) e doutoranda pelo PROARQ-UFRJ - na área de teoria, história e crítica da arquitetura - desde 2017. Graduação em Arquitetura e Urbanismo e em Ciências Econômicas. Professora da PUC-Rio desde 2009, delybentes@gmail.com usjt

\section{arq.urb}

número 30 |jan-abr de 2021 Recebido: $19 / 08 / 2020$
Aceito: $12 / 03 / 2021$

DOI: $10.37916 /$ arq.urb.vi30.462

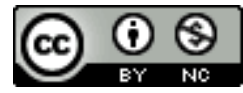

\section{Palavras-chave:}

Arquitetos.

Clientes.

Mercado consumidor

\section{Keywords:}

Architects.

Clients.

Consumer Market.

\section{Resumo}

O ponto de partida da reflexão aqui proposta é o inventário de 192 edições da revista Casa e Jardim, entre os anos de 1977 e 1992. À luz da teoria da comunicação e da sociologia - representados por autores como Mike Featherstone (1995), Pierre Bourdieu (2007) e Garry Stevens (2003) -, pretende-se esquadrinhar as reportagens, editoriais e a publicidade, em busca de sutilezas nas entrelinhas dos textos e imagens. Esta análise permite enxergar como a publicação colabora com a organização do campo profissional em um momento de expansão do mercado, ajudando a estabelecer os parâmetros para o exercício cotidiano dos arquitetos, e especialmente a sua relação com os clientes. Paralelamente, a inabilidade do meio acadêmico em lidar com esta realidade - o que resulta na exclusão de parte do produto da disciplina do registro histórico e da crítica - é problematizada.

\section{Abstract}

The starting point for this reflection is the inventory of 192 editions of Casa e Jardim magazine, between the years 1977 and 1992. In the light of the theory of communication and sociology - represented by authors such as Mike Featherstone (1995), Pierre Bourdieu (2007) and Garry Stevens (2003) -, it is intended to scan the reports, editorials and advertising, looking for subtleties between the lines of the texts and images. This analysis allows us to see how the publication collaborates with the organization of the professional field in a time of market expansion, helping to establish the parameters for the daily exercise of architects, and especially their relationship with clients. At the same time the inability of the university in dealing with this reality - which results in the exclusion of part of the disciplinary product from the historical record and criticism - is problematized. 


\section{Apresentação}

A configuração histórica da arquitetura como profissão se baseou na produção de edifícios excepcionais, idealizados por indivíduos especialmente talentosos, cuja função social, segundo Garry Stevens, se traduzia em "produzir edifícios de poder e gosto para pessoas de poder e gosto" (2003, p.244). É fato que alguns eventos ajudaram a solidificar a visão elitista do ofício, como a postura autoritária dos arquitetos modernos, ou mesmo a dicotomia plantada por Pevsner, entre projeto de arquitetura e simples construção (1982, p.7). Apesar de todas as mudanças políticas, sociais e econômicas levadas a cabo, principalmente a partir da segunda metade do século XX, esta antiga estrutura parece ainda ecoar na forma como se organiza o campo profissional, a despeito de que as condições originais não sejam (e não possam mais ser) as mesmas. Fernando Diez, em sua tese doutoral, reitera que os edifícios projetados por indivíduos legitimados como arquitetos - no sentido de terem cumprido as exigências institucionais e legais para tal - não devem ser excluídos, embora reconheça que esta "seja realmente uma das atitudes mais difundidas nos círculos acadêmicos. Uma solução 'simples' para a presença embaraçosa dessa maioria do que se constrói." (2005, p.11, grifo nosso).

Certamente não se trata de pensar que todo o produto disciplinar seja unificado sob condições homogêneas de elaboração e construção e o próprio Diez propõe uma separação ao organizar o produto entre "arquitetura de proposição" e "arquitetura de produção". A primeira, segundo ao autor, é projetada e construída em condições particulares, amplamente publicada e reconhecida pela crítica arquitetônica por suas qualidades exemplares. Com frequência está ligada aos círculos acadêmicos. A segunda, por outro lado, é aquela que responde às demandas da encomenda e está sujeita a restrições de toda sorte. Porém, por ser quantitativamente prevalente, molda e dá forma às cidades (DIEZ, 2005, p.11). A existência dessa diferença, contudo, não deve ser colocada em termos qualitativos. Não parece razoável pressupor que a arquitetura de qualidade apenas possa ser realizada em condições excepcionais. Esta visão excludente, que não reconhece os edifícios produzidos pela lógica comercial, como também seus idealizadores, igualmente restringe o registro histó-
Campo profissional e arquitetura nos anos 1980. Um olhar através da revista "Casa e Jardim" rico e a investigação do que, na prática, representa a maior parte do ambiente construído".

Portanto, parece necessário que estas fontes sejam incluídas nas pesquisas que envolvem a produção, bem como na historiografia recente da arquitetura. Paul Golberger aponta nesta direção e afirma que "o que é certo é que é impossível pensar seriamente sobre arquitetura hoje em dia e não pensar no ambiente construído como um todo" (GOLDBERGER, 2009, p.3), caminho que já havia sido apontado por Robert Venturi, Denise Scott Brown e Steven Izenour ainda no início da década de 1970, como deixam claro na passagem de sua publicação, "Aprendendo com Las Vegas"

Aprender com a paisagem existente é, para o arquiteto, uma maneira de ser revolucionário. Não do modo óbvio, que é derrubar Paris e começar tudo de novo, como Le Corbusier sugeriu na década de 1920, mas de outro, mais tolerante, isto é, questionar o modo como vemos as coisas. (...) os arquitetos perderam o hábito de olhar para o ambiente sem emitir julgamentos (...). (VENTURI; SCOTT BROWN; IZENOUR, 2003, p.25)

Apesar da tentativa desses importantes teóricos em trazer para dentro da academia a discussão acerca do banal, a história mostra que não houve uma via de continuidade para este ímpeto pop. No entanto, o interesse por essa temática parece haver sido retomado no cenário internacional a partir do final da década de 1990, o que pode ser percebido através da produção de textos e seminários, como a publicação capitaneada pela crítica e historiadora Beatriz Colomina, intitulada "Cold war hothouses: inventing postwar culture, from cockpit to playboy" (2004). A metodologia empregada pela autora na pesquisa que deu origem ao livro deixa claro que se trata menos de arquitetura (e de sua autonomia) e mais sobre as transformações nas relações estabelecidas a partir do final da II Guerra. O que buscava não estava nas publicações profissionais ou nos grandes edifícios, mas nas revistas populares, nos anúncios, filmes e programas de TV. (COLOMINA; BRENNAN; KIM, 2004, p.11). Portanto, ela procurava ali, e não nos compêndios de arquitetura, a face mais cotidiana da disciplina e o que poderia ser extraído daquele universo. A questão levantada no seminário que subsidiou a publicação de Colomina foi a de uma mudança no papel do arquiteto, especialmente em relação à busca de suas referências e em

${ }^{1}$ cf. DUNHAN-JONES, 2000. 
sua postura mais receptiva e menos prescritiva. Na nova realidade de mudanças cada vez mais rápidas, de desenvolvimento da indústria cultural e dos meios de comunicação de massa, o protagonismo se invertera e os arquitetos deveriam, então, ser os intérpretes dessa nova sociedade, ou como diriam Venturi e Scott Brown, aprender com ela.

As reflexões aqui propostas estão baseadas em um levantamento que escrutinou todas as edições da revista Casa e Jardim (CJ) entre os anos de 1977 e 1992. O resultado foi a catalogação de 633 projetos de residências unifamiliares, desenhados por 454 profissionais diferentes. Além dos projetos, também os editoriais, matérias e a propaganda foram examinados. A escolha da fonte de investigação, a revista CJ, já denota a vontade de se aproximar do tipo de produção de mercado frequentemente desconsiderada nos meios acadêmicos. Portanto, na leitura sugerida, interessa especialmente examinar como a revista $\mathrm{CJ}$ apresenta esta arquitetura e os profissionais aos seus leitores, em última análise também seus consumidores.

Parece importante pontuar que a revista Casa e Jardim publica projetos de residências unifamiliares, destinadas às classes média e alta. Este programa - o da casa burguesa - é um tema controverso na pesquisa em arquitetura e, de modo geral, só se legitima quando está a serviço da investigação erudita. Oriol Bohigas dedica um artigo às "casas para ricos" (BOHIGAS, 1969, p.87). Neste texto de 1969, o catalão rechaça a discriminação apriorística de um programa por seu potencial mais ou menos transformador, ou mais ou menos vanguardista ou reacionário, restando ao arquiteto a missão de lidar com ética diante de cada projeto que se apresente (p.90-1). Em outras palavras, Bohigas admite ser válido projetar para a burguesia, desde que preservadas a autonomia da arquitetura e dos arquitetos. João Masao Kamita, também endossa este ponto de vista ao afirmar que a casa é "nossa natureza morta, local das experimentações poéticas e das inovações formais". (Kamita, 2004 , p. 3). Nos projetos de residências, muitas vezes suas próprias, os arquitetos testam suas teorias, experimentam ideias e assim materializam o seu pensamento.

2O período denominado "milagre econômico" se estendeu entre os anos de 1969 e 1973. Neste intervalo, na sequência do Golpe Militar de 1964 e do endurecimento do regime a partir da promulgação do Al-5 em 1968, o país registrou altas taxas de crescimento mantidas artificialmente pela grande participação do Estado na economia. No entanto, o primeiro choque do petróleo em 1974, inaugurou um longo período de hiperinflação e estagnação do crescimento.
Campo profissional e arquitetura nos anos 1980. Um olhar através da revista "Casa e Jardim"

Mas, e no contexto do ofício do arquiteto, seria possível preservar esta isenção ou seria necessário aceitar e enfrentar as contingências? Torna-se oportuno reproduzir aqui o questionamento de Ruth Verde Zein no artigo publicado em 1987: "É claro que tal situação é criticável (...). Mas e daí? Que fará o colega que necessita trabaIhar e viver? (2010, p.155)

Diante destas ponderações iniciais, procura-se, através da observação da linguagem verbal e não-verbal que acompanha os projetos apresentados, identificar o papel social do arquiteto no cenário de mudanças deflagradas no Brasil a partir da crise que sucedeu o período de pujança do milagre econômico ${ }^{2}$. Neste contexto, a ampliação do mercado e a busca por espaço profissional tornou necessário o enfrentamento do aspecto comercial da arquitetura, bem como a controversa relação com os contratantes. À luz da teoria da comunicação e da sociologia, representados por autores como Mike Featherstone (1995), Pierre Bourdieu (2007), Anthony Giddens (2002) e Garry Stevens (2003), pretende-se esquadrinhar os textos, imagens e a propaganda em busca de sutilezas que ajudem na interpretação da face mais cotidiana da profissão e a maneira como os meios de comunicação - através do estudo de caso da revista Casa e Jardim - ajudam a moldar a arquitetura e os arquitetos, e especialmente a sua relação com os clientes.

\section{Fonte e recorte}

A revista Casa e Jardim enquadra-se na rubrica "revista de consumo", como são chamadas pelo mercado editorial as "publicações destinadas ao grande público, vendidas em bancas ou em outros pontos de varejo" (CORRÊA, 2008, p.207). No período de análise a quantidade de títulos listados na retranca "Arquitetura e Decoração" do Anuário Brasileiro de Mídia $^{3}$, oscilou entre 12 e 17. Neste universo, porém, encontram-se não apenas as revistas de consumo - a própria Casa e Jardim e outros títulos similares como Casa Claudia e Casa Vogue - mas também as revistas ditas especializadas, aquelas "que interessam a segmentos específicos de grupos de profissionais" (CORRÊA. 2008, p.207), como Módulo e Projeto. Dentre aquelas

${ }^{3} \mathrm{O}$ Anuário Brasileiro de Mídia é uma robusta publicação anual editada, à época, pela editora "Publinform", e distribuída gratuitamente entre as agências de propaganda e os anunciantes. Para esta pesquisa foram consultadas todas as edições referentes aos anos do recorte. 
destinadas ao público leigo, a escolha da CJ justifica-se através de seu perfil editorial, que publicava também projetos de arquitetura, diferente de outras cujo foco principal eram as matérias sobre decoração de interiores. Além disto, esteve no mercado durante todos os anos do recorte ${ }^{4}$, além de possuir expressiva tiragem algo em torno de 60 mil exemplares por mês em 1977, até cerca de 90 mil em $1992^{5}$. A título de comparação, um anúncio da revista Projeto publicado no Anuário Brasileiro de Mídia do biênio 86/87 faz referência a uma tiragem de 18 mil exemplares.

A revista CJ é pioneira no movimento que o mercado editorial convencionou chamar de segmentação, em que as revistas passam a abordar temas específicos, em contraposição à ideia de uma publicação generalista, que, nos idos dos anos 1950, era suprida pela "O Cruzeiro" do grupo de Chateaubriand. Paula Merlino, na dissertação de mestrado que versa sobre os primeiros anos da revista, assim a classifica:

(...) optamos por considerá-la como uma publicação de interesse específico sobre arquitetura, porém direcionada ao público leigo, composto principalmente por nãoarquitetos, de classe média ou alta, proprietários ou locatários de imóveis com interesse por assuntos relacionados à construção ou à manutenção da casa e às questões da família. Segundo os objetivos propostos pelos editores, ela se constitui num instrumento de divulgação das possibilidades da moderna arquitetura brasileira e das novas tecnologias à disposição da construção. (MERLINO, 2007, p.28)

Embora as revistas de arquitetura e decoração sejam usualmente categorizadas como "femininas", Merlino rechaça este rótulo para a CJ, o que é corroborado pela opinião da arquiteta carioca Rachel Sisson, frequente colaboradora da revista e entrevistada pela autora, que além disso, acrescenta tratar-se de uma publicação "nem direcionada ao público leigo, nem ao público especialista, mas a todo tipo de pessoa que possuísse alguma relação com o espaço." (SISSON apud MERLINO, 2007, p.29). De fato, a leitura dos exemplares mais recentes - entre 1977 e 1992 - confirma essa impressão.

De forma análoga à fonte documental escolhida, o recorte temporal se propõe a vislumbrar um panorama ampliado sobre a década de 1980, que ainda parece

${ }^{4} \mathrm{O}$ título foi lançado em 1953 pela editora Monumenta. Em 1965 foi comprado pela editora Efecê, que o publicou até 1998, quando finalmente passou ao controle da editora Globo, onde permanece até os dias atuais.
Campo profissional e arquitetura nos anos 1980. Um olhar através da revista "Casa e Jardim"

possuir muitos hiatos a serem preenchidos pela pesquisa em arquitetura de forma a rever a alcunha de década perdida. Essa denominação, oriunda da grave crise econômica em que o Brasil esteve mergulhado nesse período, com inflação alta e baixos níveis de investimento, acabou por se estender à produção da arquitetura, que além de sofrer os impactos da escassez de meios e recursos, também se debatia com os questionamentos do seu próprio campo em transformação. Maria Alice Bastos e Ruth Verde Zein, no extenso painel da recente arquitetura brasileira, "Brasil: arquiteturas após 1950", argumentam que "nos anos de 1980, o pretenso 'fim da modernidade' se manifestou em um ímpeto de catarse orgiástica característico, manifestando a dúvida da crise: que fazer? (...)" (2010, p.289). Porém as mesmas autoras reconhecem o potencial daquele período quando se referem, ainda na mesma publicação, à "(...) enorme abertura de perspectivas obtida pela profícua década de crises (...)" (p.292, grifo nosso).

\section{Contexto}

Para o Brasil, os anos que se estenderam entre 1950 e o final da década de 1970 foram decisivos no sentido da "construção de uma economia moderna, incorporando os padrões de produção e de consumo próprios aos países desenvolvidos." (MELLO; NOVAIS, 2004, p.562) e embora as consequências do modelo de desenvolvimento adotado tenham se feito sentir anos mais tarde, no processo de hiperinflação, endividamento e queda de investimentos que se instalou no país já na década de 1980, é inegável que tenha impulsionado a ascensão social e o surgimento de uma nova classe média com maior acesso ao ensino superior ${ }^{6}$ (p.632). Esta nova classe se tornaria grande consumidora de bens de consumo e sua relação com as empresas e a propaganda, viriam a estabelecer as bases da indústria cultural no país. Porém, o novo público precisaria ser "educado", nos termos em que sinaliza Mike Featherstone, de modo a solidificar novos mercados, o que, segundo o sociólogo inglês, ocorre através da publicidade e da mídia (1995, p.32). Em suas palavras, os grupos aspirantes devem se comportar como aprendizes e, portanto, para eles, "são muito importantes as revistas, jornais, livros e programas de rádio e

${ }^{5}$ Estes dados foram fornecidos pelo Sr. Gilberto Barricatti, ex diretor comercial da revista Casa e Jardim, durante entrevista realizada pela autora.

${ }^{6}$ João Manoel Cardoso de Mello e Fernando Novais quantificam este dado com o número de 1,4 milhão de universitários matriculados em 1980, contra 95 mil em 1960 (2004, p.132). 
televisão associados à cultura de consumo" (p.38). Segundo Pierre Bourdieu, para pleitear um lugar respeitável nesta sociedade estratificada, a nova burguesia precisa adquirir capital cultural que compense a falta do capital social herdado, o qual não possuem (2007, p. 290). Esse papel é exercido pelo grupo que o sociólogo inicialmente denomina taste makers:

Esta (nova) economia deseja um mundo social que julga os homens tanto por suas capacidades de consumo, seu standing e estilo de vida, quanto por suas capacidades de produção. Ela encontra seus porta-vozes convencidos na nova burguesia dos vendedores de bens e serviços simbólicos, empresários e quadros de empresas de turismo e jornalismo, de imprensa e cinema, de moda e publicidade, de decoração e promoção imobiliária: por seus conselhos deliberadamente imperativos e pelo exemplo de uma arte de viver que eles vivem como exemplar, os novos taste makers propõem uma moral reduzida a uma arte de consumir, gastar e usufruir. (BOURDIEU, 2007, p.291)

Através da análise das edições da revista CJ à luz destas formulações da teoria do consumo, é possível perceber que existe um sistema bem engendrado baseado na sequência de proposição, reforço e validação das ideias que são apresentadas sejam elas de caráter objetivo, como materiais e novos produtos, ou subjetivos e imateriais. Este mecanismo torna-se possível pela atuação conjunta de editores, redatores, arquitetos e anunciantes. Para enfrentar este dado é necessário assumir a forte interdependência que se instala entre esses atores a partir do pleno estabelecimento do capitalismo pós-industrial, da sociedade de consumo e dos meios de comunicação de massa. Na revista CJ fica evidente o caráter educativo de suas matérias e o quanto a editoria se ancora nos arquitetos para a construção e consolidação de seus ideais.

Através da propaganda e das matérias encomendadas, fica flagrante o quanto a indústria trata de ajustar seus produtos de forma a deixá-los em consonância com o ideal formatado, ou até mesmo antecipar-se criando as demandas para os produtos que pretendem lançar. A mercadoria aparece ali como colaboradora para a efetivação da promessa de conforto ou segurança e, no campo mais abstrato, de um estilo de vida, que Anthony Giddens define como "um conjunto mais ou menos integrado de práticas que um indivíduo abraça, não só porque essas práticas preenchem necessidades utilitárias, mas porque dão forma material a uma narrativa
Campo profissional e arquitetura nos anos 1980. Um olhar através da revista "Casa e Jardim" particular da auto identidade." (2002, p.79). Através desse expediente se instaura uma semiologia própria, estruturada pelo cruzamento de textos e imagens, de maneira a definir significados reforçando e validando símbolos e signos que muitas vezes extrapolam o simples intuito de classificação arquitetônica, mas que estão comprometidos nesse sistema maior.

No contexto da revista, não só nos textos explicativos dos projetos, como também nas reportagens e nos anúncios publicitários, nas fotografias e nas opiniões dos arquitetos e especialistas, esses ideais são então plasmados e reforçados. $\mathrm{O}$ apoio à credibilidade dos arquitetos é, nesse sentido, fundamental, para que possam colaborar com a engrenagem. Ao longo de período pesquisado, é possível perceber diferentes abordagens que a revista adotou para completar este objetivo.

\section{Linhas e entrelinhas \\ Arquitetos como intermediários culturais}

Os arquitetos são profissionais que se encaixam apropriadamente na definição dos taste makers de Bourdieu, também chamados de intermediários culturais, justamente por exercerem o papel de tradutores e intérpretes para as novas classes aspirantes. Dar voz e destaque a eles foi uma estratégia bastante utilizada pela CJ no começo dos anos 1980, quando foi implementado um modelo de apresentação de projetos que incluía não só o retrato do arquiteto, como também um pequeno currículo descrevendo sua formação e experiência, seguindo o molde do que está apresentado com o arquiteto Ricardo Julião (Figura 1). Uma parte de seu texto exemplifica a maneira como a revista busca incentivar a posição do cliente e sua relação com o arquiteto: "A opinião do cliente é muito respeitada, desde que não entre em conflito com a arquitetura contemporânea, com as realidades da época, do clima, da topografia do terreno, de um todo, enfim"'. 


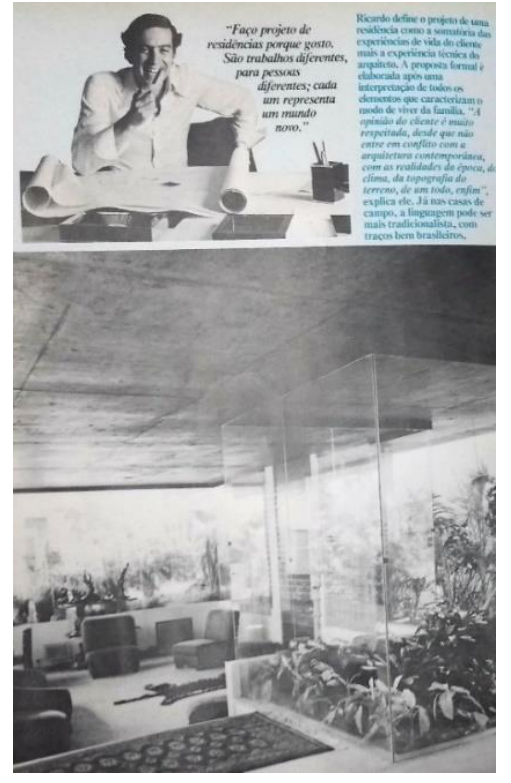

Figura 1: Ricardo Julião. Fonte: CJ 302, p.42 (março de 1980).

Na edição 304, de maio de 1980, uma residência em concreto aparente e tijolos cerâmicos, coberta por uma grande laje ajardinada perfurada por domus de acrílico ocupa seis páginas da revista CJ. A matéria enfatiza, já no seu lead", o teor "inusitado" do projeto. O texto descritivo que acompanha as fotografias e desenhos da residência deixa evidente o papel de mediador cultural que o arquiteto exerceu perante os seus clientes: "O projeto, bastante arrojado na sua proposição, foi recebido com certa relutância pela família que desejava uma casa mais tradicional, a partir da leitura de revistas especializadas (...."'.9. Pitanga do Amparo, autor do projeto, é, portanto, quem traduz para os proprietários da casa no Morumbi - à maneira de Bourdieu - o modo de vida contemporâneo, como o próprio arquiteto acredita representar. Vale reproduzir um trecho do texto que acompanha a fotografia do arquiteto na reportagem em questão:

${ }^{8} \mathrm{O}$ lead jornalístico é o parágrafo inicial da notícia, onde devem estar respondidas as questões quem? o quê? onde? como? por quê? cf.ABREU, 2002, p.10

${ }^{9} \mathrm{CJ} 304$, p.32
Campo profissional e arquitetura nos anos 1980. Um olhar através da revista "Casa e Jardim"

Contrário a estilos e modismos, não faz concessões quanto à arquitetura propriamente dita, mas procura seguir o programa do cliente, de forma a adaptá-lo aos conceitos de uma arquitetura contemporânea. "Só faço casa em estilo colonial se o cliente vier de carruagem", ironiza ele para acentuar a impropriedade de reproduzir estilos de outras épocas e regiões. ${ }^{10}$

Toda a construção textual da reportagem, deixa clara a função de mediação atribuída ao arquiteto e a editoria da revista endossa este papel. A mesma estratégia aparece ainda no projeto assinado por Michail Lieders, Carlos Ferro e Marcos Acayaba, na edição 314, de março de 1981. Mais uma vez a apresentação da residência é antecedida pelo relato do processo de convencimento dos profissionais ante a demanda inicial dos clientes: "influenciada pelos arquitetos, a família, constituída por casal com dois filhos jovens, abandonou a ideia de construir uma residência tradicional, aceitando um projeto avançado e singular (...)"11. O resultado se traduz em espaços voltados para o interior do lote, contornando jardins e uma piscina, num volume prismático definido por grandes vãos de concreto aparente e extensos panos envidraçados. Nas entrelinhas, portanto, esta é a forma como se apresenta aos leitores a maneira contemporânea de morar.

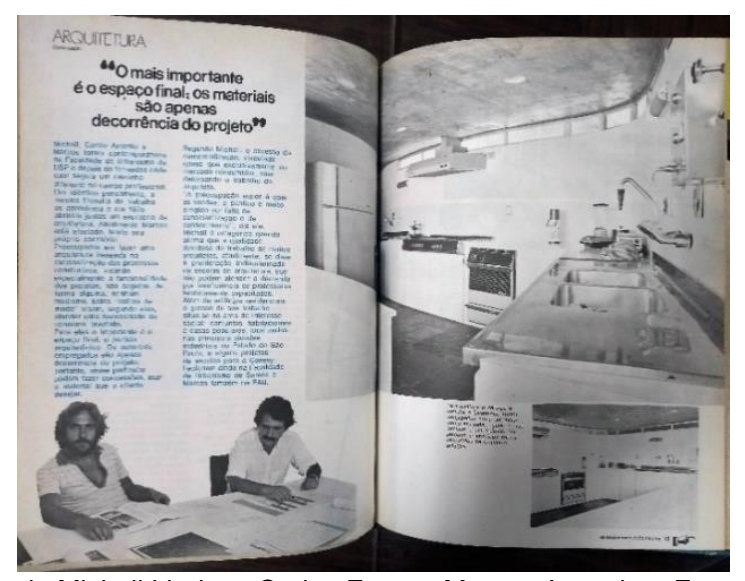

Figura 2: Projeto de Michail Lieders, Carlos Ferro e Marcos Acayaba. Fonte: CJ 314 p.84-85 (março de 1981)

${ }^{10} \mathrm{CJ} 304$, p.34, grifo nosso

${ }^{11}$ CJ 314 p. 80 . 
Das sete páginas utilizadas para a apresentação do projeto, uma inteira se presta à apresentação dos arquitetos e de suas ideias. Neste espaço, Michael Lieders e Carlos Ferro (Figura 2) dissertam sobre a profissão e o ato de projetar. No texto, se declaram "preocupados em fazer uma arquitetura baseada na racionalização dos processos construtivos, visando especialmente a funcionalidade dos projetos". ${ }^{2}$, além de se dizerem avessos a modismos. De acordo com Lieders, o excesso de comercialização, vinculado quase que exclusivamente ao mercado consumidor, estaria deturpando o trabalho do arquiteto. Ele é "categórico quando afirma que a qualidade duvidosa do trabalho de muitos arquitetos, atualmente, se deve à proliferação indiscriminada de escolas de arquitetura, que não podem atender à demanda por insuficiência de professores tecnicamente qualificados"13. É de se notar a percepção que estes profissionais manifestam a respeito do campo profissional e da formação dos arquitetos, especialmente no que diz respeito ao aumento das escolas, que de fato é compatível com o panorama de crescimento do período ${ }^{14}$.

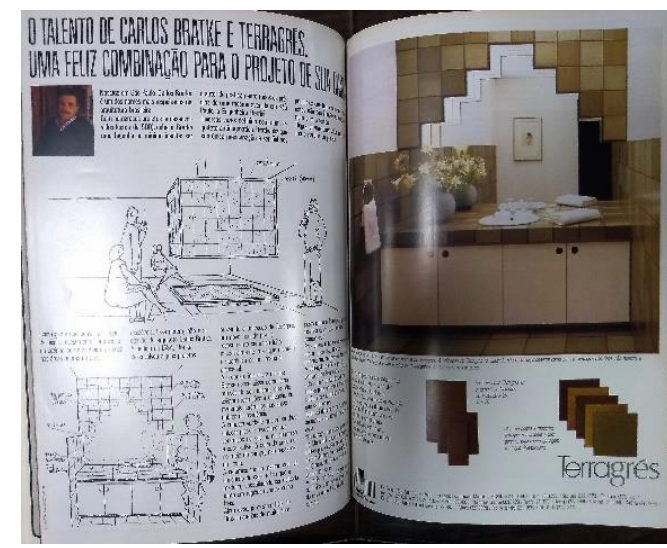

Figura 3: Carlos Bratke e Terragrés. Fonte: CJ 385 p. 14 (fevereiro de 1987)

\section{${ }^{12}$ CJ 314, p. 84}

${ }^{13}$ CJ 314 p.84.

${ }^{14} U$ m levantamento realizado pela ABEA (associação brasileira de escolas de arquitetura) em 2014, com base em dados disponibilizados pelo portal do Ministério da Educação, mostra como a abertura de novos cursos de arquitetura acelerou em proporção geométrica entre os anos de 1970 e 1990 quando o crescimento foi equivalente a $178 \%$, chegando ao número de 53 faculdades de arquitetura no país. O aumento exponencial é registrado a partir de 1988, quando a nova Constituição passou
Campo profissional e arquitetura nos anos 1980. Um olhar através da revista "Casa e Jardim"

$\mathrm{O}$ conflito de interesses insinuado pelo arquiteto Michail Lieders com relação à prática profissional e o mercado consumidor não impede, porém, que as empresas anunciantes se valham da confiança que as matérias e reportagens emprestam aos arquitetos, para então colocá-los como avalizadores dos produtos oferecidos pela indústria. Nesse caso, a estratégia é semelhante à utilizada pela revista, onde as qualificações do profissional são enaltecidas, para em seguida o mesmo atestar a qualidade do produto. A fabricante de pisos e azulejos Ornato publicou uma peça publicitária na edição 292, de maio de 1979, em que apresenta um projeto de Roberto Burle Marx. O título - "Uma obra do talento de Roberto Burle Marx" - e a apresentação do arquiteto paisagista, que faz menção ao prêmio oferecido pelo conjunto de sua obra ${ }^{15}$, enfatizam a qualificação do profissional, cujo texto em primeira pessoa legitima o produto anunciado.

A mesma estratégia voltaria a aparecer, em 1987, na propaganda da fabricante de cerâmica Terragrés protagonizada pelo arquiteto Carlos Bratke (Figura 3). Ao lado de seu retrato, o arquiteto é apresentado como um dos "nomes mais respeitados da arquitetura brasileira (...) e autor de quase todos os prédios de uma mesma avenida em São Paulo, a Engenheiro Berrini" ${ }^{16}$. Além da imagem do produto, desenhos e um longo texto preenchem a página dupla. $O$ talento e a expertise de Bratke se prestam, neste caso, a endossar a utilização do revestimento cerâmico em áreas nobres da residência. Com o objetivo claro de ampliar seu mercado consumidor, a empresa recorre à experiência pessoal do arquiteto, que afirma ter construído sua casa no Morumbi utilizando pisos cerâmicos em todos os ambientes. Neste caso, portanto, ele atua como um legítimo formador de opinião.

$\mathrm{Na}$ edição 285, uma propaganda do condomínio de casas Arco Baleno, em São Paulo, faz referência às experiências americana e europeia para lastrear a solução proposta pela incorporadora CYREL $^{17}$ para a implantação de um condomínio de casas. Apenas três edições depois, no volume 288, de janeiro de 1979, na matéria

a permitir à iniciativa privada obter lucro com o ensino. Em 2014, o mesmo levantamento registra 369 cursos no país. Este levantamento foi apresentado durante o XX Congresso brasileiro de arquitetos e obtido pela autora.

${ }^{15}$ Trata-se da Fine Arts Medal, recebida em Washington em 1965

${ }^{16} \mathrm{CJ} 385$, p. 14

${ }^{17}$ Trata-se da atual Cyrela. 
intitulada "Solução simples para viver melhor"18, o arquiteto Cleber Vieira da Rocha fala sobre a tendência de se morar nos bairros planejados afastados da cidade e as justificativas para tal escolha. Nesta operação fica clara a estratégia de proposição, reforço e validação referida anteriormente.

\section{Arquitetos e clientes}

Nos textos que acompanham os projetos é recorrente a menção à usabilidade da casa e seu custo. Neles, os clientes são colocados em posição de protagonistas e a revista se esforça em criar uma identificação com eles que são, em última instância, seus consumidores finais. Em uma entrevista realizada com a jornalista Olga Samilla ${ }^{19}$, esta impressão pode ser confirmada: "A gente achava importante mostrar pra quem foi feito esse projeto exatamente naquele sentido: opa! É uma família igual a minha! Puxa, também tenho três filhos jovens! Puxa, também posso ter uma casa como essa, que legal!". ${ }^{20}$ Portanto, incentivados pela filosofia editorial que pautava a publicação, os arquitetos sempre eram encorajados, ainda segunda sua então redatora, a falar sobre esse ponto.

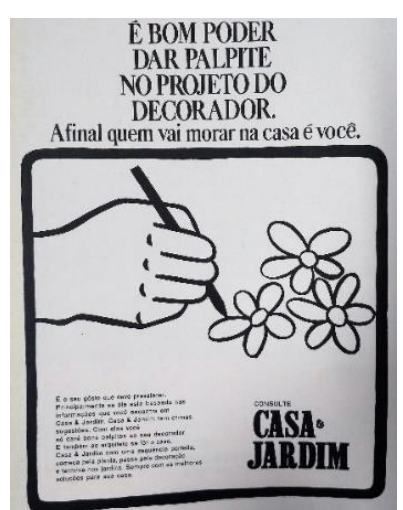

Figura 4: Propaganda da revista Casa \& Jardim. Fonte: CJ 285 p.89. (outubro de 1978)

${ }^{18} \mathrm{O}$ bairro planejado Alphaville foi pioneiro na implantação deste modelo de moradia em São Paulo No caso do Rio de Janeiro, o bairro da Barra da Tijuca viria a ser o lugar por excelência dos chamados "condomínios fechados", com a inaugurac̃a também na década de 1970, de Nova Ipanemados "condomínios fechados", com a inauguração, tambem na década de 1970, de Nova Ipanema e Novo Leblon.

${ }^{19} \mathrm{~A}$ Sra. Olga Regina Samilla entrou para a redação da revista CJ em 1978 e lá permaneceu, assumindo diferentes posições incluindo o de redatora chefe - até 1991.
Campo profissional e arquitetura nos anos 1980. Um olhar através da revista "Casa e Jardim"

Neste contexto, Nicole Evelyne Reiss, arquiteta que assina um dos projetos da edição 317, de junho de 1981, dispara: "O conteúdo é próprio do morador; a forma que é do arquiteto". E continua: "se o arquiteto procura impingir ao proprietário algo que não é dele, este acaba não assimilando a obra depois de realizada. E o resultado é um falseamento da vivência do morador." ${ }^{21}$ Em outra matéria, de agosto de 1981, o arquiteto Matias Mercier enfatiza a ideia da convivência harmoniosa e flexível no seu testemunhal: "O trabalho que proporciona mais satisfação é aquele que dá para sentir a alegria do cliente com o resultado. Ou seja, uma interação entre arquiteto e proprietário. Flexível, acredita que a arquitetura deve atender ao usuário e não criar 'a casa que está na minha cabeça'”22. Na fala destes dois profissionais já é possível perceber uma mudança na maneira de lidar com a encomenda.

De modo geral, acolher a opinião dos proprietários parece uma ideia a ser valorizada e muitas vezes utilizada como mote principal do desenvolvimento dos projetos. A revista parece apoiar essa proposta, pois publicou um anúncio em suas páginas cuja chamada, "É bom dar palpite no projeto do decorador. Afinal quem vai morar na casa é você" (Figura 4), expõe sem rodeios este posicionamento e consequentemente, o caráter mercadológico que permeia a relação. Além de posicionar o arquiteto (chamado de decorador, no caso em tela) como um prestador de serviços contratado para desenvolver um projeto, esta postura coloca o cliente e o profissional em patamares iguais, denunciando uma flexibilização da relação, especialmente em comparação com a realidade dos arquitetos modernos, cujos reflexos ainda se percebiam com clareza nos exemplos mostrados pela revista até o início da década de 1980, como nos casos de Pitanga do Amparo e Lieders, Ferro e Acayaba, apresentados anteriormente.

Na seção "Depoimento", da edição 291, de abril de 1979, o arquiteto Arnaldo Conceição Paiva, fala sobre o processo de projetar uma casa para uma família e como equacionar as vontades desta com a sua expertise e conhecimentos técnicos, que, ao longo do texto, o autor descreve com frases como: "Eis um problema para um

${ }^{20} \mathrm{~A}$ entrevista foi transcrita sem fazer adaptações para a norma culta, portanto, expressões coloquiais típicas da língua falada podem aparecer sempre que trechos dela sejam reproduzidos.

${ }^{21}$ CJ 317 p.83.

${ }^{22}$ CJ 319 p. 96 . 
arquiteto. Ele possui a sua arquitetura, a sua maneira de ser, mas não é ele que vai morar na casa", ou como o trecho a seguir: "Tem que ser racional; uma família é dinâmica, amanhã as necessidades serão outras, talvez um dia seja preciso vender a casa e, se ela for muito personalizada, será difícil achar outra família igual para comprá-la"23. Neste sentido, conforme avançam os anos 1980, as matérias buscam estabelecer uma mediação entre clientes e arquitetos, se preocupando em desfazer a imagem do profissional excêntrico que privilegia as decisões estéticas e éticas baseadas exclusivamente em suas crenças, ante parâmetros de ordem mais pragmática, como orçamentos e manutenção ou até mesmo os desejos de seus contratantes.

A colaboração entre arquiteto e morador também aparece como um ponto relevante para os discursos que estão relacionados aos projetos. A ideia é sempre reforçar as vantagens da cooperação entre ambos. O projeto publicado na edição 401, de junho de 1988, é um bom exemplo disto: “(...) com ampla participação da família em todas as etapas, do orçamento à construção, esta casa mostra como a funcionalidade pode estar aliada a boas soluções arquitetônicas". ${ }^{24}$. Este texto deixa subentendida a crença na incompatibilidade entre um bom projeto $e o$ atendimento às questões funcionais e técnicas do programa - o que as lendárias histórias que envolvem o desprezo de Le Corbusier ou Frank Lloyd Wright às questões de ordem pragmática ajudaram a construir ${ }^{25}$. Nesta e em outras passagens, é possível observar que a revista desempenha um papel conciliador em relação aos arquitetos e ao seu ofício. Aproximá-los do mundo real e das necessidades mais vulgares e cotidianas do projeto arquitetônico, numa tentativa de desmistificar a ideia de que o projeto não é para todos ou que sempre gera soluções caras e de difícil execução e manutenção. O pequeno trecho reproduzido abaixo, extraído da apresentação de um projeto na edição de agosto de 1979, traz à tona alguns pontos cruciais que permeiam a profissão:

Com uma postura bastante realista a respeito do problema da conciliação entre a criatividade do arquiteto e a proposta do morador, Sami Bussab procurou atender às expectativas, acrescentando inovações, de forma a não interferirem na maneira de ser dos proprietários. Nesta casa, projetada para um casal de três
Campo profissional e arquitetura nos anos 1980. Um olhar através da revista "Casa e Jardim"

filhos jovens, de hábitos tradicionais, não se adequariam propostas de espacialidade ou elementos muito avançados. ${ }^{26}$

Em único parágrafo dois temas relevantes para o entendimento da formação do campo profissional da arquitetura são levantados. O primeiro trata do que Edson Mahfuz denomina "mito da criatividade" dos arquitetos. Segundo o crítico, a associação equivocada que os "(...) leigos (usuários em geral, clientes, imprensa não especializada), estudantes de primeiros anos e até muitos arquitetos, (de que a) criatividade é algo ligado ao imprevisto, ao insólito, (...), cuja obtenção é dependente de um talento superior inato" (MAHFUZ, 2003), prejudica a formação do campo, na medida em que gera expectativas equivocadas sobre o projeto de arquitetura. $O$ segundo ponto polêmico apresentado acima é o da controversa relação dos arquitetos com seus contratantes. O cenário, anteriormente comentado, do incremento das escolas de arquitetura e, consequentemente, do número de arquitetos formados, aponta para o que Garry Stevens chama de novos profissionais emergentes, a grande "massa de praticantes" que, segundo o autor, constitui o "setor subordinado" (2003, p. 244) da profissão. Em sua análise, o setor dominante, detentor de maior capital simbólico, prescinde da aprovação dos seus patronos e, ao contrário, "podem dizer aos clientes o que é bom para eles, pois assim fazendo eles definem a superioridade simbólica do cliente" (p.114).

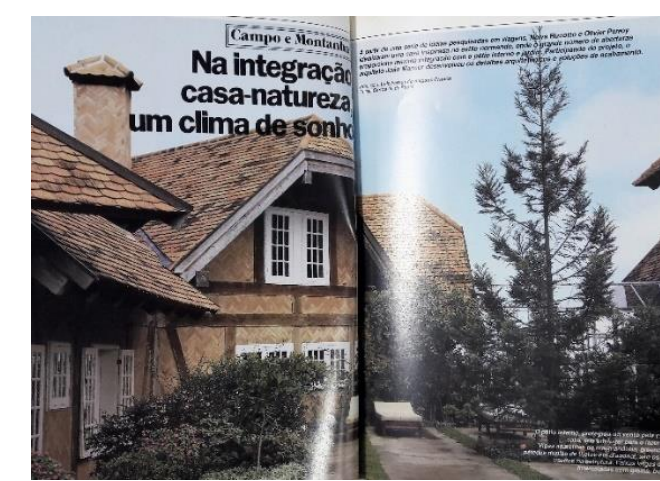

Figura 5: Projeto de João Mansur. Fonte: CJ 413 p.60-61 (junho de 1989)

${ }^{25} \mathrm{cf}$. STEVENS, 2003, p.103

${ }^{26} \mathrm{CJ} 295$ p.36, grifo nosso. 
A popularização da arquitetura, parece se intensificar no Brasil durante o último quartel do século $\mathrm{XX}$, quando ocorre o aumento da oferta de profissionais ${ }^{27}$ - mais arquitetos formados pelas crescentes escolas - e a expansão do seu mercado consumidor - uma classe média que emergiu no período da ditadura militar. No entanto, pelas características históricas do campo, esse contingente não viria a se organizar de forma homogênea, mas dividindo-se em grupos, tal como apresentados por Stevens: o setor dominante e o setor subordinado de arquitetos (2013, p.244), divididos entre os subcampos restrito e de massa (p.100). De certa forma, esse evento termina por macular a antiga função social do arquiteto, que era produzir edifícios excepcionais para membros da elite, o que ainda se mantém apenas no caso dos arquitetos de maior representatividade simbólica.

Seguindo esta dinâmica, apenas os profissionais que constituem o setor subordinado da profissão precisam lidar com as trivialidades, necessidades e desejos de seus contratantes. O que a revista apresenta, através da fala dos profissionais, parece ser a concretização desta, então recente, lógica de relacionamento entre arquitetos e usuários. Esta dinâmica, baseada em traduzir e entender as demandas e expectativas da família, significa inclusive negociar. Isso fica claro também na descrição a seguir, da matéria intitulada "Prática e funcional, para o campo", publicada na edição 367, de agosto de 1985: "A finalidade do arquiteto Pedro Henrique de Almeida foi elaborar um projeto de tal forma que atendesse a todas as necessidades do cliente: uma obra de recreação e lazer para os fins de semana de uma família pequena, mas socialmente ativa"28

A apresentação do projeto de uma casa, já no final dos anos 1980, dá sinais da radicalização desse modus operandi. Além do título, já muito significativo: "Na integração casa-natureza, um clima de sonho" (figura 5), o parágrafo inicial também traz subtextos relevantes:

A partir de uma série de ideias pesquisadas em viagens, Neiva Rizzoto e Olivier Perroy idealizaram uma casa inspirada no estilo normando, onde o grande número de aberturas proporciona máxima integração com o pátio interno e jardim.

${ }^{27} \mathrm{O}$ mesmo levantamento da ABEA anteriormente mencionado registra 369 cursos no ano de 2014. O aumento exponencial é registrado a partir de 1988, quando a nova Constituição permite à iniciativa privada obter lucro com o ensino, liberando a criação de escolas particulares não confessionais.

${ }^{28} \mathrm{CJ} 367$ p.58
Campo profissional e arquitetura nos anos 1980. Um olhar através da revista "Casa e Jardim"

Participando do projeto, o arquiteto João Mansur desenvolveu os detalhes arquitetônicos e soluções de acabamento. ${ }^{29}$

A passagem coloca os proprietários como idealizadores do projeto e o arquiteto aparece em um papel coadjuvante, o que é ratificado pelo trecho grifado acima. $O$ profissional atua como uma espécie de facilitador, responsável apenas por traduzir tecnicamente a "casa de sonhos" dos contratantes. Já em 1992, a edição 451 traz a matéria "Panorama da arquitetura atual"30, com os depoimentos de vários arquitetos e também de Gilberto Belleza, à época presidente do Instituto de Arquitetos do Brasil (IAB). Entre outros assuntos, Belleza disserta sobre os projetos residenciais e a atuação profissional e o trecho a seguir corrobora o ponto atual da argumentação: "No projeto de casas, que possibilita maior liberdade de intervenções, tudo deve ser muito bem planejado. E o arquiteto tem o dever de diagnosticar as necessidades das pessoas e oferecer alternativas e soluções (...)"31. Através da fala institucionalizada do então presidente do IAB, a revista reitera o papel de prestadora de serviços que vem reforçando, de forma cada vez mais enfática, por todo o período pesquisado. No mesmo ano de 1992, sob o título de "Descubra o mais novo conceito de morar", a revista apresenta uma reportagem que traz depoimentos de arquitetos como João Armentano e Arthur de Mattos Casas. Embora o foco seja a decoração de interiores, algumas ideias são reforçadas: "o papel do arquiteto não é vender um estilo de vida, mas sim diagramar o modo de viver para os clientes". 32 Através destes discursos que intermedia, a revista atua como uma espécie de portavoz do campo profissional em expansão, ao mesmo tempo em que ajuda a moldar uma forma de atuação, ocupando um espaço vazio que a universidade, via de regra, não julga necessário preencher.

\section{Algumas leituras}

A apreciação das reportagens, propagandas e editoriais permite verificar que a revista se posiciona, através dos discursos que intermedia, como uma fornecedora de referências e modelos de arquitetura e de prática profissional, bem como de modos de viver, em cooperação direta com a indústria e com os arquitetos. No entanto, o

\footnotetext{
${ }^{29} \mathrm{CJ} 413$ p.63, grifo nosso.

${ }^{30} \mathrm{CJ} 451$ p. $18-21$

${ }^{31} \mathrm{CJ} 451$ p.20, grifo nosso.

${ }^{32} \mathrm{CJ} 452$ p. 16
} 
conteúdo deste texto parece se alterar ao longo da década de 1980, denunciando mudanças nesses critérios e, especialmente, um novo tipo de relação profissional. Essa década parece ter testemunhado mudanças significativas no contexto social e econômico do país, que terminaram por modificar também as bases referenciais dos projetos de arquitetura, e muito especialmente em relação ao programa das casas unifamiliares. Estas alterações, contudo, já haviam sido percebidas ainda na década de 1950 pelo casal Alison e Peter Smithson. O trecho de seu artigo intitulado "But today we collect ads"33, publicado originalmente em 1956 é bastante elucidativo desta posição:

A vida comum está recebendo impulsos poderosos de uma nova fonte. Onde, há trinta anos, os arquitetos encontraram no campo das artes populares, técnicas e estímulos formais, hoje estamos sendo desafiados em nosso papel tradicional pelo novo fenômeno das artes populares - a propaganda. A publicidade dos produtos de consumo de massa está estabelecendo todo um novo padrão de vida princípios, ética, objetivos, aspirações e modos de viver. Devemos, de alguma forma, avaliar essa intervenção se quisermos combinar seus impulsos poderosos e excitantes com os nossos. (2003, p.44, tradução nossa, grifo nosso.)

O que eles falam é de um "novo" vernacular, não mais um intocado e autêntico espelho de técnicas construtivas e modos de viver de culturas e civilizações distantes - que em muito Paul Rudofsky e o MoMA ${ }^{34}$ contribuíram a conduzir ao topo do pensamento erudito sobre as manifestações arquitetônicas corriqueiras -, posteriormente traduzidas em importantes chaves de leitura, como o regionalismo crítico de Kenneth Frampton (2006, p.503). Os Smithsons se referem ao produto contaminado da sociedade de consumo, intermediado pela propaganda e por novos modos de vida hedonista. Era também esse o objetivo de Robert Venturi e Denise Scott Brown quando empreenderam a sua pesquisa nos subúrbios de classe média da Pensilvânia, buscando "aprender com "Levittown ${ }^{35}$. Ao contrário de Rudofsky, a

${ }^{33} \mathrm{Em}$ tradução livre: "Mas hoje nós colecionamos anúncios".

${ }^{34} \mathrm{Em} 1964$ foi organizada uma exposição no MoMA (acompanhada de uma publicação) com o produto da pesquisa do arquiteto Bernard Rudofsky, intitulada "Architecture without architects, an introduction to nonpedigreed architecture", em que arquiteturas espontâneas de mais de 60 países visitados pelo arquiteto foram apresentadas como manifestações autênticas da sabedoria construtiva daquelas diferentes culturas.

${ }^{35}$ Levittown foi um conjunto de comunidades planejadas construídas por uma firma chamada Levitt \& sons. Foram os primeiros e maiores subúrbios construídos em massa, para atender à demanda
Campo profissional e arquitetura nos anos 1980. Um olhar através da revista "Casa e Jardim" pesquisa completa do casal de arquitetos jamais foi publicada ${ }^{36}$, o que pode ter ajudado a manter esta temática como um tabu. Assim, mercado, clientes, ofício seguem sendo realidades incômodas com as quais os que pensam arquitetura preferem não lidar, como colocado de forma incisiva pelas palavras de Fernando Diez, nos contornos iniciais desta discussão. No entanto, apesar da negação, ela não deixa de existir e aparece de forma cristalina nas páginas da revista CJ.

E o que ela nos mostra é que os quase dez anos que separam a fala firme de Pitanga do Amparo - que aceita negociar, mas que, no limite de suas convicções profissionais, se recusa a projetar uma casa em estilo colonial - e a postura leniente de João Mansur - o arquiteto que traduz em chalé normando o sonho de seus clientes -, são sintomáticos das transformações sugeridas, o que pode ser interpretado com uma perda de autonomia, mas também como uma necessidade de estabelecer uma relação de fato dialética com os contratantes - afinal, relembrando Zein, os arquitetos precisam "trabalhar e viver". As diferentes posturas também revelam formações e atuações distintas. A ideia da arquitetura como um serviço, ou mesmo da existência de um cliente é um fato tratado com desconforto pelos arquitetos - ao menos os do setor dominante. Este incômodo faz com que o produto do mercado e os seus idealizadores - quem nunca ouviu a frase "Isso não é arquitetura!"- sejam desconsiderados. Porém, esta rejeição ou mesmo a inabilidade em lidar com a inevitável realidade da existência de um mercado, parece não reconhecer que "o dia a dia do arquiteto não é feito de grandes gestos ou de oportunidades ímpares, e sim do exercer cotidianamente seu ofício (ZEIN, 2010, p.153).

Assim, estas conclusões só reforçam a necessidade do enfrentamento da questão. Com o rigor da pesquisa científica esta arquitetura precisa ser (re)conhecida de maneira a criar subsídios para repensar o papel da disciplina e dos arquitetos na realidade atual. Seguir desconsiderando-os não irá gerar ações propositivas que

de moradia do pós-guerra. (havia, inclusive, planos especiais para veteranos). Foram construídos em New York (1957), Pensilvânia (1952), Nova Jérsei (1958) e Porto Rico (1963).

${ }^{36}$ Beatriz Colomina, em seu comentário sobre o tema, especula que este fato, em parte, se deva às inúmeras críticas que receberam na época (COLOMINA, 2011). Esta experiência do casal Venturi Scott Brown conta como um dos estudos de caso da pesquisa colaborativa intitulada "Radical pedagogies", que a autora mantém na Universidade de Princeton colaborativa intitulada "Radical pedagogies", que a autora mantiven gies.com/search-cases/a14-new-haven-denise-ScottBrown-robert-venturi-learning-levittown-yale-
school-architecture/ 
reverberem no ensino ou na atuação profissional. Legitimar esta produção e encarar os seus desdobramentos, contudo, não significa elevá-la a protagonista. É preciso percorrer os interstícios da história da arquitetura moderna em busca das suas fragmentações, mas sem, contudo, elevá-las a mitos, como afirmam Tafuri e Dal Co (1979, p.9). Já é tempo de entender que há várias histórias da arquitetura que cursam em paralelo, histórias que não podem e nem devem ser confrontadas qualitativamente, posto que ocupam diferentes espaços e são produzidas em condições e com propósitos únicos. Incluir esta produção demonstra generosidade, senão com o mercado, mas com os arquitetos que atuam no mercado e que precisam "trabalhar e viver". Além disso, parece ser um passo necessário para buscar melhoras para o ambiente construído.

\section{Referências}

ABREU, Alzira Alves de. A modernização da imprensa (1970-2000). Rio de janeiro: Zahar, 2002.

BASTOS, Maria Alice Junqueira; ZEIN, Ruth Verde. Brasil: arquiteturas após 1950. São Paulo: Perspectiva, 2010.

BOURDIEU, Pierre. A distinção: crítica social do julgamento. São Paulo: EDUSP, 2007.

COLOMINA, Beatriz; BRENNAN, AnnMarie; KIM, Jeannie. Cold war hothouses: inventing postwar culture, from cockpit to playboy. Massachusetts: The MIT Press, 2007. Edição do Kindle.

Mourning the Suburbs: Learning from Levittown. In: Public Journal. Issue 43: Suburbs. Toronto, 2011.CORRÊA, Thomaz Souto. A era das revistas de consumo. In: Martins, Ana Luiza; LUCA, Tânia Regina de. História da imprensa no Brasil. São Paulo: Editora Contexto, 2013.

DUNHAM-JONES. Ellen. Seventy-Five Percent. In: Sprawl and Spectacle. Harvard Design Magazine, ed.12. Cambridge: Harvard University Graduate School of Design, 2000.

FEATHERSTONE, Mike. Cultura de consumo e pós-modernismo. São Paulo: Studio Nobel, 1995.
Campo profissional e arquitetura nos anos 1980. Um olhar através da revista "Casa e Jardim" FRAMPTON, Kenneth. Perspectivas para um regionalismo crítico. In: NESBITT, Kate (org.). Uma nova agenda para a arquitetura. Antologia teórica 1965-1995. São Paulo: Cosac Naify, 2006.

GIDDENS, Anthony. Modernidade e identidade. Rio de Janeiro: Zahar, 2002.

GOLDBERGER, Paul. Why Architecture Matters. New Haven: Yale University Press, 2009.

KAMITA, João Masao. The modern Brazilian house. IN: FORTY, Adrian; ANDREOTTI, Elisabetta. Brazil's Modern Architecture. London: Phaidon, 2004.MAHFUZ, Edson. O mito da criatividade em arquitetura. In: Coluna Relações, Info IAB/RS, Disponível em:< http://www. iab-rs. org. br/colunas/artigo. Php, 2003. (acesso em 12/5/2019)

MELLO, João Manuel Cardoso de; NOVAIS, Fernando. Capitalismo tardio e sociabilidade moderna. In: SCWARTZ, Lilia Moritz (org.). História da vida privada no Brasil: contrastes da intimidade contemporânea. V.4. São Paulo: Editora Companhia das letras, 2004.

MERLINO, Paula. Casa e Jardim: a revista e a divulgação do ideário moderno na década de 1950. Dissertação (Mestrado em arquitetura) - Universidade Federal do Rio de Janeiro. Faculdade de Arquitetura. PROARQ. 2007.

PEVSNER. Nikolaus. Panorama da arquitetura ocidental. São Paulo: Martins Fontes, 1982.

SMITHSON, Alison; SMITHSON, Peter. But today we collect ads. In: L'Architecture d'aujoud'hui, n. 344, 2003, p.44-45.STEVENS, Garry. O círculo privilegiado: Fundamentos sociais da distinção arquitetônica. Brasília: Editora Universidade de Brasília, 2003.

TAFURI, Manfredo; DAL CO, Francesco. Modern Architecture. New York: Harry N. Abrams, 1979.

VENTURI, Robert; SCOTT BROWN, Denise; IZENOUR, Steven. Aprendendo com Las Vegas: o simbolismo (esquecido) da Forma Arquitetônica. São Paulo: Cosac \& Naify, 2003. 
ZEIN, Ruth Verde. O futuro do passado ou as tendências atuais. In:GUERRA, Abílio (org.). Textos fundamentais sobre história da arquitetura moderna brasileira_parte 1. São Paulo: Romano Guerra, 2010.

\section{Revista:}

Casa \& Jardim. São Paulo: Editora Efecê, n.291, ago.1979.

Casa \& Jardim. São Paulo: Editora Efecê, n.295, abr.1979.

Casa \& Jardim. São Paulo: Editora Efecê, n.302, mar.1980.

Casa \& Jardim. São Paulo: Editora Efecê, n.304, abr.1980.

Casa \& Jardim. São Paulo: Editora Efecê, n.314, mar.1981.

Casa \& Jardim. São Paulo: Editora Efecê, n.317, jun.1981.

Casa \& Jardim. São Paulo: Editora Efecê, n.319, ago.1981.

Casa \& Jardim. São Paulo: Editora Efecê, n.335, dez.1982.

Casa \& Jardim. São Paulo: Editora Efecê, n.367, ago.1985.

Casa \& Jardim. São Paulo: Editora Efecê, n.385, fev.1987.

Casa \& Jardim. São Paulo: Editora Efecê, n.401, jun. 1988.

Casa \& Jardim. São Paulo: Editora Efecê, n.413, jun.1989.

Casa \& Jardim. São Paulo: Editora Efecê, n.451, ago.1992.

Casa \& Jardim. São Paulo: Editora Efecê, n.452, set.1992.

\section{Entrevistas:}

Entrevista realizada com a jornalista Olga Samilla, redatora da revista Casa \& Jardim durante o período pesquisado. São Paulo, 4/06/2019.

Entrevista realizada com a jornalista Gilberto Barricatti, diretor comercial da revista Casa \& Jardim durante o período pesquisado. São Paulo, 4/06/2019. 